\title{
Auscultatory and phonocardiographic findings in autologous fascia lata valves
}

\author{
Leonard Schwartz, Alan S. Trimble, and John E. Morch ${ }^{1}$ \\ From the Departments of Medicine and Division of Cardiovascular Surgery \\ and The Cardiovascular Unit, ${ }^{2}$ Toronto General Hospital, Toronto, Ontario, Canada
}

Of a total of 30 autologous fascia lata aortic, mitral, and tricuspid valve replacements in 25 patients, opening sounds were heard or recorded in association with 24 valves. Murmurs were heard during forward flow across 26 of the valves. In no patients did the sounds or murmurs develop or progress during the period of follow-up but were present immediately after operation. It is felt that these auscultatory findings are a result of the manner in which the valve is constructed and are associated with normal function of the valve.

Senning (1967) introduced the use of autologous fascia lata in the replacement of deformed aortic valve cusps, and in early 1969 Ionescu modified this technique by mounting autologous fascia lata onto a stent to form a three-cusped valve for aortic and atrioventricular replacement (Ionescu et al., 1970). Potential attributes of this new valve included central flow characteristics, ease of insertion, absence of thromboembolism, and avoidance of anticoagulants. For these reasons, fascia lata valves have been used in a consecutive series of patients at the Toronto General Hospital. The following report documents the auscultatory and phonocardiographic findings in 25 patients who underwent such valve replacements. This information will permit recognition of the auscultatory phenomena associated with normal function of this valve and facilitate postoperative evaluation.

\section{Methods}

Twenty-five of the patients who underwent single, double, or triple autologous fascia lata valve replacements (Table I) at the Toronto General Hospital between November 1969 and April 1970 were studied. The heart sounds and murmurs were documented by auscultation in the immediate postoperative period (often in the recovery room). In I6 patients phonocardiograms were taken two weeks after operation. Repeat observations were made 6 months after operation in 7 patients.

\footnotetext{
Received 23 November 1970.
}

${ }^{1}$ Address for reprints: J. E. Morch, Cardiovascular Unit, Toronto General Hospital, IOI College Street, Toronto ror, Ontario, Canada.

2 Supported by the Ontario Heart Foundation.
The electrocardiogram, phonocardiogram, and carotid pulse tracing or apex cardiogram were recorded simultaneously on an Electronics for Medicine DRI2 Model. Phonocardiograms were recorded at end expiration in the 100 to 500 cycles a second range, unless otherwise indicated.

Site of recordings: 4L5: 4th intercostal space, left side, $5 \mathrm{~cm}$ from median line; 5 Lro: 5 th intercostal space, left side, $10 \mathrm{~cm}$ from median line.

FIG. I An autologous fascia lata valve.

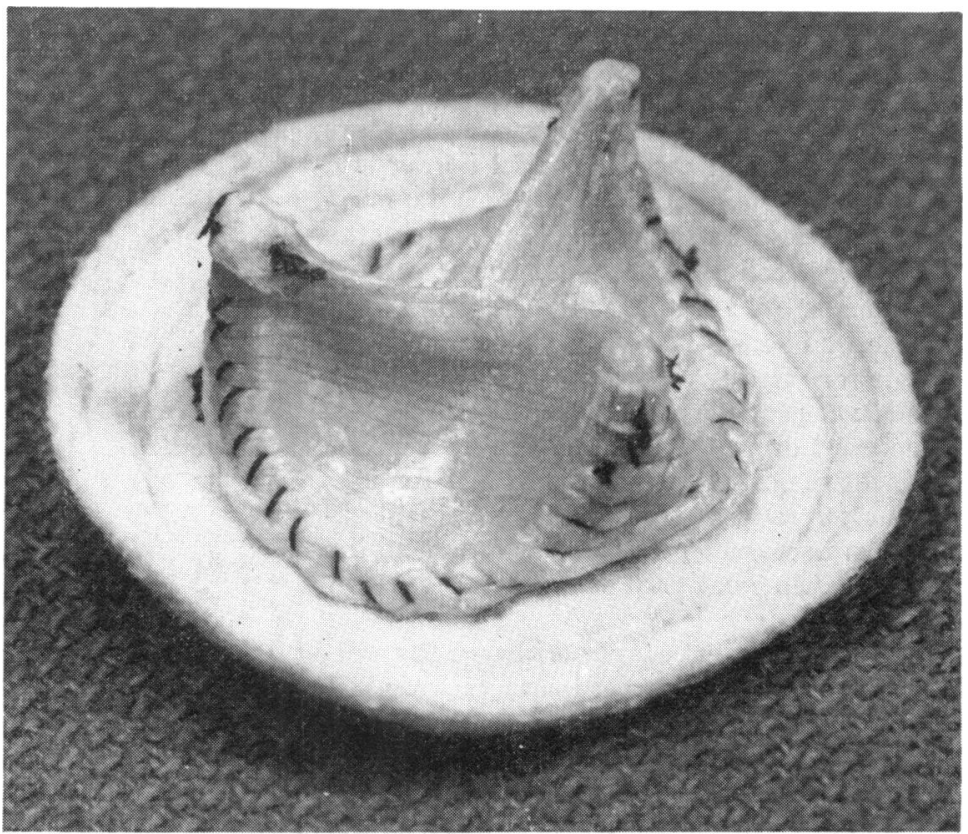


TABLE I Distribution of patients

\begin{tabular}{lc}
\hline Valve replaced & No. of patients \\
\hline Aortic & I8 \\
Mitral & 3 \\
Mitral and tricuspid & 3 \\
Aortic, mitral, and tricuspid & I \\
\hline
\end{tabular}

TABLE 2 Aortic fascia lata valve replacements

\begin{tabular}{llll}
\hline $\begin{array}{l}\text { No. of } \\
\text { patients }\end{array}$ & $\begin{array}{l}\text { Internal } \\
\text { frame } \\
\text { diameter } \\
(\mathrm{mm})\end{array}$ & $\begin{array}{l}\text { Aortic open- } \\
\text { ing sound } \\
\text { (heard or } \\
\text { recorded })\end{array}$ & $\begin{array}{l}\text { Systolic mur- } \\
\text { mur (heard or } \\
\text { recorded })\end{array}$ \\
\hline 6 & 20 & 4 & 5 \\
10 & 22 & 6 & 9 \\
2 & 24 & 2 & 2 \\
\hline 18 & & 12 & 16 \\
\hline
\end{tabular}

\section{Results}

Aortic valve replacements of the 18 patients with fascia lata aortic valve replacement, early systolic sounds were heard in 9. These sounds, confirmed by phonocardiograms in 5, were most easily heard and recorded along the left sternal border particularly at the 4th intercostal space. Simultaneous phonocardiographic and carotid pulse tracings showed that this aortic opening sound occurred at the time of aortic valve opening and left ventricular ejection (Tavel, I967) (Fig. 2). In 3 patients the opening sound was recorded but not heard, and in the remaining 6 patients an opening sound was neither heard nor recorded. In 16 of 18 patients with aortic valve replacements ejection systolic murmurs were heard down the left sternal border and in the 9 who had phonocardiograms the murmur was also recorded (Fig. 2). Murmurs were not heard or recorded in the remaining 2 patients. In all aortic valve replacements, the second sound was accentuated and either single or closely split. In one patient, a grade $1 / 6$ early diastolic decrescendo murmur was heard down the left sternal border in the immediate postoperative period. The findings in the 18 patients with aortic valve replacement are set out in Table 2 according to the internal diameter of the valve ring.

Mitral valve replacements Early diastolic sounds were heard and recorded at the apex in all 3 patients with mitral valve replacements. These sounds occurred at 0.08 to 0.1 sec after the second heart sound at the time of the $\mathrm{O}$ point of the apex cardio-

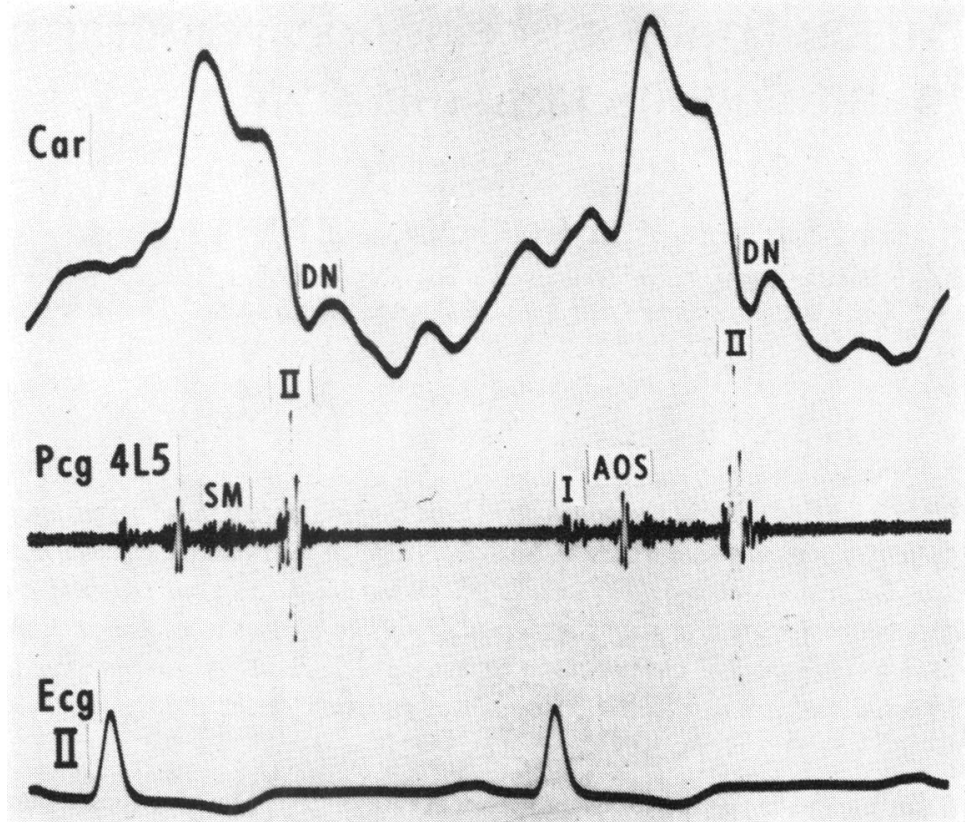

FIG. 2 Simultaneous carotid pulse tracing, phonocardiogram, and electrocardiogram in a patient with an autologous fascia lata aortic valve, demonstrating the aortic opening sound and the ejection systolic murmur.

FIG. 3 Simultaneous apex cardiogram and phonocardiogram in a patient with an autologous fascia lata mitral valve, demonstrating the mitral opening sound and diastolic murmur.

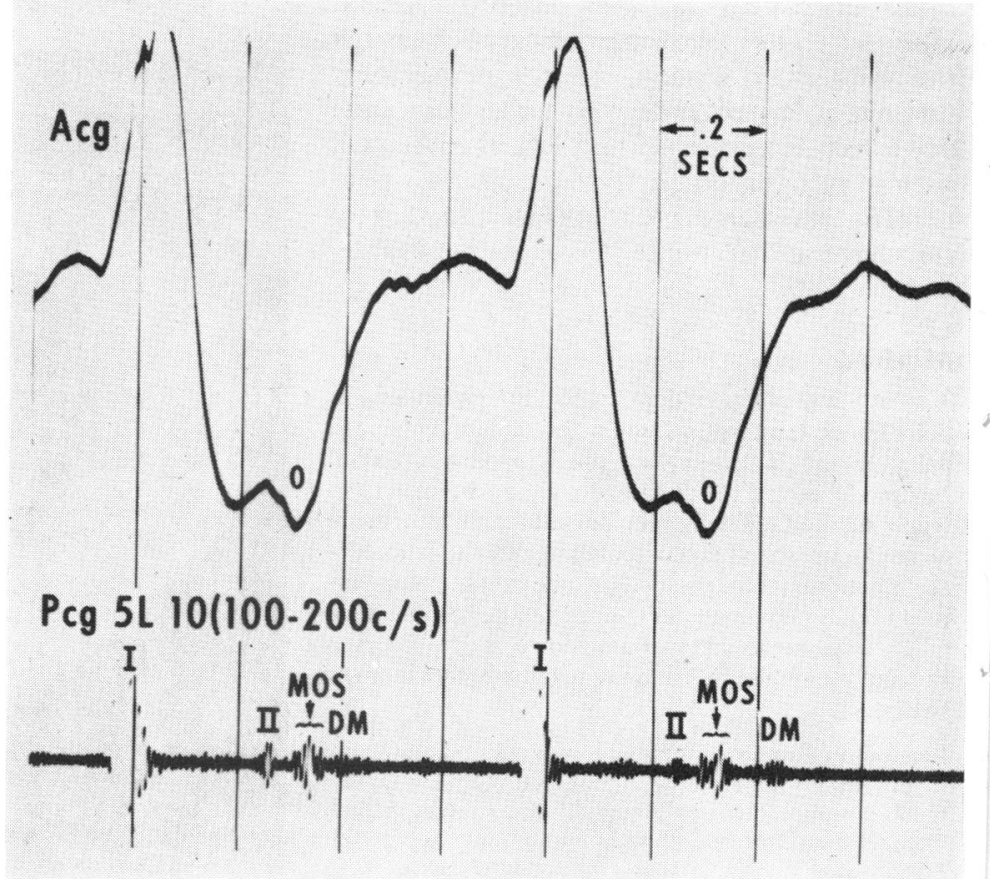




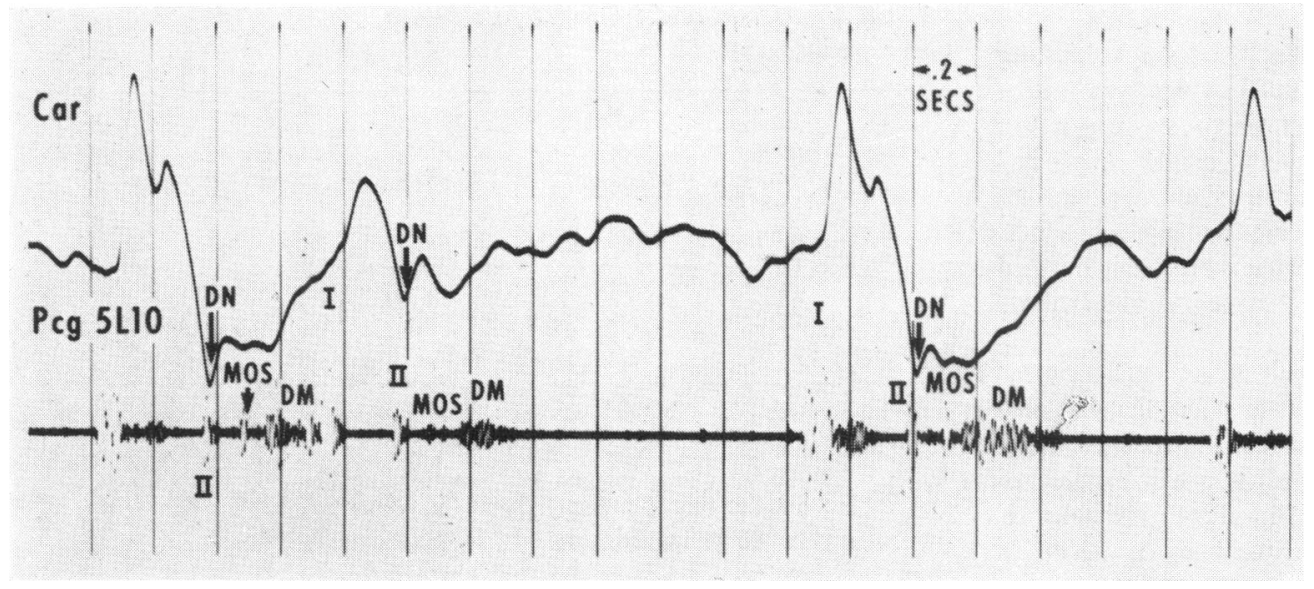

$A$

TABLE 3 Mitral fascia lata valve replacements

\begin{tabular}{llll}
\hline $\begin{array}{l}\text { No. of } \\
\text { patients }\end{array}$ & $\begin{array}{l}\text { Internal } \\
\text { frame } \\
\text { diameter } \\
(\mathrm{mm})\end{array}$ & $\begin{array}{l}\text { Mitral } \\
\text { opening } \\
\text { sound } \\
\text { (heard and! } \\
\text { or recorded) }\end{array}$ & $\begin{array}{l}\text { Diastolic } \\
\text { murmur } \\
\text { (heard and/or } \\
\text { recorded) }\end{array}$ \\
\hline 3 & 26 & 3 & 2 \\
\hline
\end{tabular}

gram (Fig. 3). In 2 of the 3 patients middiastolic murmurs were heard and recorded at the apex (Fig. 3). Table 3 summarizes the findings in the group with mitral valve replacements.

Multiple valve replacements In the 3 patients with mitral and tricuspid valve replacements an early diastolic sound was heard and recorded at the apex, and in 2 of the 3 an apical diastolic murmur was heard and recorded. In addition, in these patients, loud early diastolic sounds and mid-diastolic murmurs were present at the 4 th intercostal space, left sternal border. In the patients with mitral valve replacement alone the opening sound and murmurs were not transmitted to the left sternal border, so it is likely that the vibrations heard and recorded in this location were associated with the tricuspid valve (Fig. $4 A$ and $B$ ). Table 4 summarizes the findings in this group. In the patient with the triple valve replacement a systolic ejection murmur was recorded but not heard at the 4 th intercostal space, left sternal border. Aortic, tricuspid, and mitral opening sounds were heard and recorded in this patient.

In all patients with atrioventricular valve replacements, the first sound was accentuated.
FIG. 4 Simultaneous carotid pulse tracings and phonocardiograms taken at the apex $(A)$ and the 4th intercostal space, $5 \mathrm{~cm}$ to the left of the median line $(B)$ in a patient with mitral and tricuspid valve replacements.

$B$
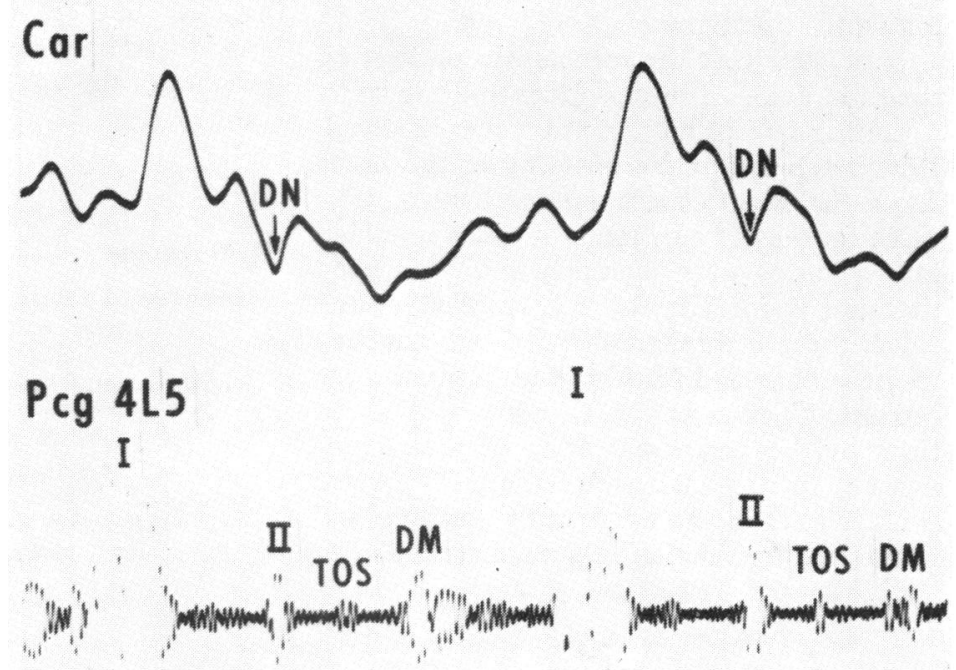

Ecg II

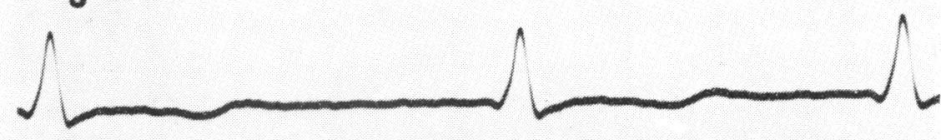




\section{Discussion}

In April of 1969 Ionescu began replacing aortic, mitral, and tricuspid valves with autologous fascia lata attached to a supporting frame. Review of the early results in $76 \mathrm{pa-}$ tients showed that all had normal heart sounds after mitral and tricuspid replacements. Grade I systolic murmurs were heard in all patients with aortic valve replacements (Ionescu et al., 1970).

In our study, auscultation and phonocardiograms revealed that the first sound after mitral and tricuspid valve replacement and the second sound after aortic valve replacement closely resembled normal sounds but were increased in intensity. In 16 of 18 patients with aortic valve replacements, a diamond-shaped systolic murmur often preceded by an opening sound was heard. No correlation was found between the frequency of systolic murmurs or opening sounds and valve diameter. Opening sounds were commonly heard in diastole followed by a soft mid-diastolic murmur after atrioventricular valve replacement. The murmurs and sounds were documented immediately after operation, and in no case were they found to have evolved or changed in the postoperative follow-up period which in some cases was of 6 months' duration.

It is likely that the mechanism underlying the production of these sounds and murmurs is similar irrespective of the valve involved. Brief reference to the anatomy of the fascia lata valve might clarify this mechanism. The valve consists of a cylinder of fascia moulded into 3 cusps over a supporting 3-pronged titanium frame. In the construction of the valve, the 3 commissural points are attached to the prongs and fortified with a small piece of knitted Teflon velour. One suture is placed through the peripheral edge of each commissure to prevent regurgitation. The valve is made in the same way in all $\mathbf{3}$ positions and is believed to function in a manner similar to
TABLE 4 Mitral and tricuspid fascia lata valve replacements

\begin{tabular}{llllll}
\hline $\begin{array}{l}\text { No. of } \\
\text { patients }\end{array}$ & $\begin{array}{l}\text { Internal } \\
\text { frame } \\
\text { diameter of } \\
\text { both valves } \\
(\mathrm{mm})\end{array}$ & $\begin{array}{l}\text { Mitral } \\
\text { opening } \\
\text { sound }\end{array}$ & $\begin{array}{l}\text { Mid- } \\
\text { diastolic } \\
\text { murmur }\end{array}$ & $\begin{array}{l}\text { Tricuspid } \\
\text { opening } \\
\text { sound }\end{array}$ & $\begin{array}{l}\text { Tricuspid } \\
\text { opening } \\
\text { sound }\end{array}$ \\
\hline 2 & 26 & 2 & 2 & 2 & 2 \\
$\mathbf{1}$ & 28 & 1 & 1 & 1 & 0 \\
3 & 3 & 3 & 3 & 2 \\
\hline
\end{tabular}

an aortic valve except that there is slight limitation of cusp movement. It is probable that the opening sounds and murmurs are due to this limitation in valve movement during maximum flow, i.e. onset of ventricular ejection with respect to the aortic valve and early diastole with respect to the atrioventricular valves. Valve movement may also be impaired because of decreased pliability of fascia lata compared to normal cusps.

The auscultatory phenomena reported in association with the fascia lata graft valve are probably associated with normal function of this valve. Small gradients may be shown in subsequent haemodynamic follow-up investigations, but significant gradients are not anticipated because of the central flow characteristics of the valve compared to disc or ball valves.

\section{References}

Ionescu, M. I., Ross, D. N., Deac, R., Grimshaw, V. A., Taylor, S. H., Whitaker, W., and Wooler, G. H. (1970). Autologous fascia lata for heart valve replacement. Thorax, $25,46$.

Senning, Å. (1967). Fascia lata replacement of aortic valves. Fournal of Thoracic and Cardiovascular Surgery, 54, 465.

Tavel, M. E. (1967). Clinical Phonocardiography and External Pulse Recording. Year Book Medical Publishers, Chicago. 